\title{
Study of Road Performance between Rub-concrete and Normal Concrete Materials
}

\author{
Long Wang ${ }^{1, a}$, Xiaoguang Xie ${ }^{2, b}$, Lulu Fan ${ }^{3, c}$ \\ ${ }^{1}$ School of Transportation Science and Engineering, Harbin Institute of Technology, Harbin, \\ China, 150090 \\ ${ }^{2}$ School of Transportation Science and Engineering, Harbin Institute of Technology, Harbin, \\ China, 150090 \\ ${ }^{3}$ School of Transportation Science and Engineering, Harbin Institute of Technology, Harbin, \\ China, 150090 \\ ahitlongwang@sina.com, ${ }^{b} x x g 75 @ 126 . c o m,{ }^{c}$ fanlulu@163.com
}

\begin{abstract}
Keyword: rubber cement concrete; flexural modulus; damping performance; fatigue performance ; surface properties ; performance prediction
\end{abstract}

\begin{abstract}
To improve the cement concrete deformation, small toughness traditional defects, with Adding the rubber grain in the concrete to form the rubber particles concrete; flexural modulus of Rubber particles of concrete and ordinary concrete was comparative studied, two kinds of concrete damping change was analyzed by using the finite element, through three point concrete trabecular bending test, the fatigue properties were comparative researched, the rutting test methods were used in proving the rubber particles of concrete of erosion performance; According to the test made the mechanical parameters of acquired in experiments, the applying the MEPDG 2002 design method, the road surface damage state were forecasted of the two kinds of concrete pavement in the design of the end; Experiment shows that rubber particles cement concrete flexural modulus is reduced by $12 \%$ than that of ordinary cement concrete, the damping ratio increased by $30 \%$, the fatigue life have greatly improved, and surface erosion phenomenon did not happen; Theoretical analysis shows that, the rubber cement concrete panel breakage is lower $30 \%$ than ordinary concrete, Therefore, the rubber particles concrete pavement can overcome the traditional 1 defects of cement road and with has excellent road performance.
\end{abstract}

\section{Introduction}

At present, rubber particles cement concrete has achieved initial success in the application of industrial and civil architecture, such as the use of shock absorption and sound insulation function in seismic foundation, the railway sleepers and sound barriers has wide application, but it is still in the research stage in the cement concrete pavement, the researches show that the good deformation property of scrap tire rubber particle in the cement concrete has the following significance: from engineering application view, rubber particles mixed in cement concrete materials to help improve the brittleness shortcomings, promote its absorbing heat insulation, sound absorption damping performance, impact resistance and crack resistance[1];From the economic point, strongly built rubber particles of cement concrete pavement, to break the high cost of asphalt pavement monopoly situation, can promote the development of local economy[2].From the section of environmental protection, rubber particles of cement concrete to be able to deal with a large number of promotion waste tyre. Promote scrap tire the effective utilization of resources, stop to the occupation of the land by waste tires and has important significance good environmental protection prospects 
[3].Rubber particle cement concrete road performance directly related to the development of it's prospects, so this paper for rubber particles concrete bending pull performance, driving damping performance, anti-fatigue properties and surface function system research, for rubber particles in the cement concrete pavement concrete application provides scientific guidance.

\section{The Rubber Particles Cement Concrete Mixture Design}

According to the results, with $10 \%$ rubber particles instead same volume sand on cement concrete mixture design[4], rubber particles concrete with cement: water: stone 1-3cm: stone 1-2cm: sand: rubber: water reducing agent $=360: 120,675,675: 376: 15.5: 5.5$. Due to the rubber particles do not occur hydration reaction, the part replace some sand is equivalent to reduce fine aggregate, therefore, rubber particles cement concrete proportion design need reduced some water consumption compared to normal cement concrete, to meet the requirements of the mixing content workability[5].

\section{Road Performance Comparison of Rubber Particles and Ordinary Cement Concrete Materials}

The properties contrast with including the flexural strength, flexural modulus, shock absorption effect, fatigue properties and surface function five aspects.

The Flexural Strength. Highway cement concrete mixing materials requirements heavy traffic conditions 28 days folding strength not less than $5 \mathrm{MPa}$, two kind of mixture cement concrete curing to provisions of the cement flexural strength such as shown in table 1. Due to the $100 \times 100$ x $400 \mathrm{~mm}$ specimens, the flexural strength conversion coefficient is 0.85 .

Table 1 Flexural strength contrast between rubber particles concrete with normal concrete

\begin{tabular}{c|c|c|c|c}
\hline samples & number & $\begin{array}{c}\text { failure load } \\
{[\mathrm{kN}]}\end{array}$ & $\begin{array}{c}\text { flexural strength } \\
{[\mathrm{MPa}]}\end{array}$ & $\begin{array}{c}\text { average flexural } \\
\text { strength [MPa] }\end{array}$ \\
\hline \multirow{3}{*}{$\begin{array}{c}\text { normal } \\
\text { concrete }\end{array}$} & 1 & 22.8 & 5.81 & \multirow{2}{*}{5.64} \\
\cline { 2 - 4 } & 2 & 22.4 & 5.71 & \\
\hline \multirow{3}{*}{ rub-concrete } & 3 & 21.2 & 5.41 & \multirow{2}{*}{5.49} \\
\cline { 2 - 4 } & 2 & 22.6 & 5.76 & \\
\cline { 2 - 4 } & 3 & 21.3 & 5.43 & \\
\hline
\end{tabular}

By bending test results indicate that two kind of mixture bending strength are satisfy the standard requirement (more than $5 \mathrm{MPa}$ ). Rubber particles cement concrete flexural strength slightly lower than normal cement concrete, reduce the rate of $3 \%$ or so, compressive strength decline slightly big, about fell $6 \%$ or so[5]; Overall, both strength gap is not big.

Flexural Modulus. The concrete flexural elastic modulus in accordance with Highway Engineering Cement and Concrete Test Regulations (JTG T0559-2005), the use of a $100 \mathrm{~mm} \times 100$ $\mathrm{mm}$ x $400 \mathrm{~mm}$ specimens. 5 times cycle load test, take the fifth cycle of deflection value. The contrast flexural modulus of normal cement concrete and rubber particles cement concrete such as shown in table 2 . 
Table 2 The contrast flexural modulus of normal cement concrete and rub-concrete

\begin{tabular}{|c|c|c|c|c|c|}
\hline samples & $F_{0}[\mathrm{kN}]$ & $F_{0.5}[\mathrm{kN}]$ & $\Delta[\mathrm{mm}]$ & $\begin{array}{l}\text { flexural modulus } \\
{[\mathrm{GPa}]}\end{array}$ & $\begin{array}{l}\text { average flexural } \\
\text { modulus [GPa] }\end{array}$ \\
\hline \multirow{3}{*}{ normal concrete } & \multirow{3}{*}{3} & \multirow{3}{*}{11} & 0.0112 & 41.1 & \multirow{3}{*}{42.1} \\
\hline & & & 0.0109 & 42.2 & \\
\hline & & & 0.0107 & 43.0 & \\
\hline \multirow{3}{*}{ rub-concrete } & \multirow{3}{*}{3} & \multirow{3}{*}{10} & 0.0113 & 35.6 & \multirow{3}{*}{37.1} \\
\hline & & & 0.0105 & 38.3 & \\
\hline & & & 0.0108 & 37.3 & \\
\hline
\end{tabular}

Rubber particles cement concrete flexural modulus is low $5 \mathrm{GPa}$ than ordinary cement concrete reduced the rate is $12 \%$, it shows the flexible performance increase[7], through calculation, it is known that the modulus reduce $5 \mathrm{GPa}$ equivalent to total stress reducing $0.58 \mathrm{MPa}$ unit deformation ,rubber particles to join, can improve the resistance of the cement concrete cracking.

Fatigue Performance. The three point bending trabecular fatigue test is adopted in the material fatigue test machine MTS. Load test using sine wave, the loading frequency is $10 \mathrm{~Hz}[11]$, equivalent to vehicles of the speed for $60 \mathrm{~km} / \mathrm{h}$. In order to speed up fatigue test, no gap between adjacent waveform.

At the beginning of test, $0.3 \mathrm{kN}$ stress is loaded on the specimen, in order to eliminate the error caused by bad contacts; under the premise of keeping stress in the same ratio $(0.4,0.6$ and 0.8 , three kinds of stress ratio) and the same stress level (5.28 MPa, 3.96 $\mathrm{MPa}$ and 2.64 MPa), fatigue performance of normal concrete and rubber cement concrete is contrasted, the test data such as shown in table 3 and Fig. 1.

Table 3 Normal and rubber cement concrete fatigue properties contrast

\begin{tabular}{c|c|c|c|c}
\hline \multirow{2}{*}{ specimens name } & $\begin{array}{c}\text { stress } \\
\text { ratio }\end{array}$ & $\begin{array}{c}\text { stress } \\
\text { level } \\
{[\mathrm{MPa}]}\end{array}$ & $\begin{array}{c}\text { load } \\
\text { recycle } \\
\text { number[N] }\end{array}$ & $\operatorname{logN}$ \\
\hline \multirow{4}{*}{\begin{tabular}{c} 
normal-concrete \\
\cline { 2 - 5 }
\end{tabular}} & 0.8 & 5.28 & 88 & 1.94 \\
\cline { 2 - 5 } & 0.6 & 3.96 & 774 & 2.89 \\
\hline \multirow{2}{*}{$\begin{array}{c}\text { rub-concrete } \\
\text { (same stress } \\
\text { ratio) }\end{array}$} & 0.4 & 2.64 & 2732 & 3.44 \\
\cline { 2 - 5 } rub-concrete \\
(same stress & 0.6 & 3.78 & 8764 & 3.94 \\
\cline { 2 - 5 } level ) & 0.4 & 2.52 & 11356 & 4.06 \\
\cline { 2 - 5 } & 0.62 & 5.28 & 304 & 2.48 \\
\cline { 2 - 5 } & 0.41 & 2.64 & 7893 & 3.90 \\
\hline
\end{tabular}




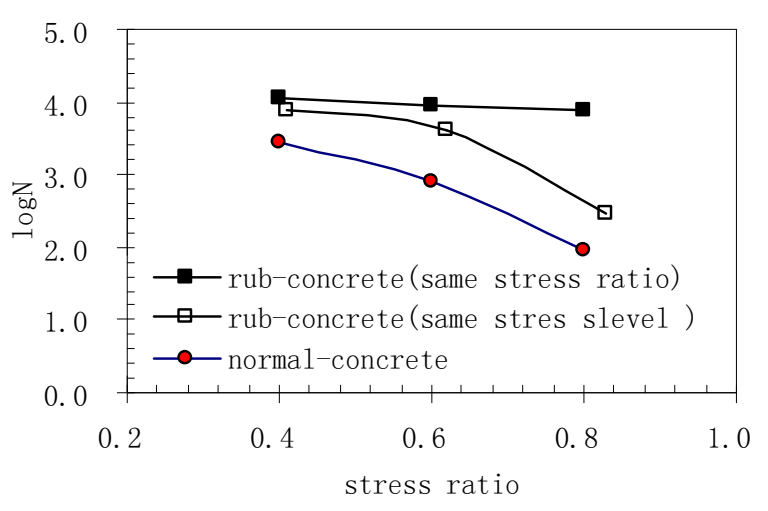

Fig. 1 Normal and rub-concrete fatigue properties contrast

Fig. 1 indicate that in the same stress than conditions, rub-concrete fatigue life is greater than normal cement concrete, with the improvement of the stress ratio, rub-concrete fatigue life is greater than that of normal concrete increased; In the same stress level, the two kinds of concrete are similar to the fatigue of the curve, the range of rub-concrete fatigue life increased basically the same under different stress level conditions. Whether using the same stress ratio and the same stress level to test, rub-concrete fatigue performance is better than normal cement concrete.

\section{Rubber Concrete and Normal Concrete Pavement Performance Prediction and Contrast}

Use the AASHTO MEPDG2002 road design guidelines; comparing using performance of two kinds of cement concrete pavement in the design age, analyzed the damage and flatness changes.

Pavement Structure. The maximum temperature gradient of experimental $\mathrm{road} 88^{\circ} \mathrm{C} / \mathrm{m}$, accumulative total axle load times is $500 \times 10^{4}$ times, belong to heavy traffic, cement concrete materials requirement flexural strength are greater than $5 \mathrm{MPa}$, pavement structure as shown in table 4. AASHTO climate model based on the database of the climate around the United States, due to the climate of Jilin province similar to the Minnesota, therefore, the climate model Minnesota adapted [12].

Table 4 The structure experimental road pavement

\begin{tabular}{c|c|c|c|c}
\hline $\begin{array}{c}\text { layer } \\
\text { number }\end{array}$ & thickness[m] & layer name & $\begin{array}{c}\text { modulus of } \\
\text { resilience[MPa] }\end{array}$ & $\begin{array}{c}\text { checking } \\
\text { total } \\
\text { stress[MPa] }\end{array}$ \\
\hline \multirow{2}{*}{1} & 0.30 & normal concrete & 42100 & 4.90 \\
\cline { 2 - 5 } & 0.28 & rub-concrete & 37100 & 4.87 \\
\hline 2 & 0.18 & cement stabilized macadam & 1800 & - \\
\hline 3 & 0.30 & lime and cement stabilized soil & 1200 & - \\
\hline 4 & 0 & soil base & 40 & - \\
\hline
\end{tabular}

Forecast Analysis Results. The change of flatness, damage of two kind of cement concrete pavement can be getting through calculation and analysis in service period; Two kinds of concrete pavement cracking rate are draw on the service years, as shown in Fig. 2. 


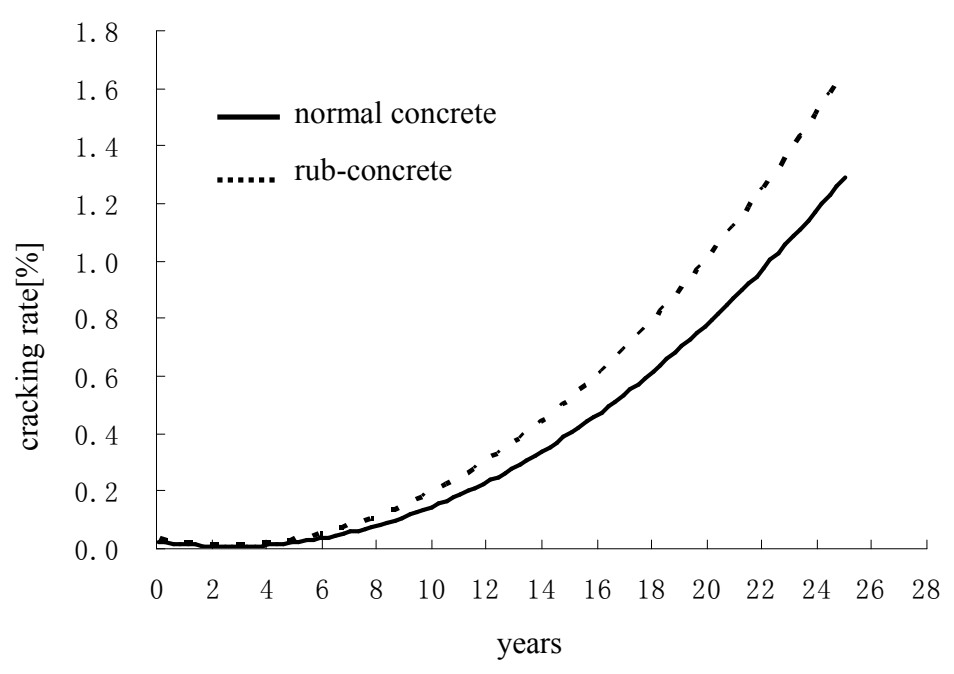

Fig. 2 Contrast of slab broken rate of two kinds of concrete pavement in different using years

From the results analysis, it is known that the IRI, cracking rate, faulting, cumulative damage of the rub-concrete pavement were less than normal concrete pavement in the end of service period. But the IRI and faulting does not significant difference. Through the Fig. 2 can see, rub-concrete pavement faulting in the process of using is far smaller than normal concrete pavement, and rub-concrete pavement Bottom-up and Top-down accumulative total crack damage also is smaller than normal concrete pavement, rub-cement concrete slab cracking rate is lower $30 \%$ than ordinary concrete slab. Therefore, in the using process, rub-concrete pavement has good flatness, and under the action of the load and climate, rub-concrete pavement disease such as cracking and slab broken are far lower than normal concrete pavement.

\section{Conclusion}

Trough the road performance comparison of normal cement concrete and rub-cement concrete, the following conclusions can be drawn:

(1) Compared to normal concrete cement concrete matrix, rub-concrete flexural strength fell by $3 \%$, compressive strength fell by $6 \%$, the flexural modulus lower by $12 \%$, but the flexural strength to meet the requirements of the design specification heavy traffic.

(2) Fatigue resistance performance of rub-concrete is superior to that of normal concrete.

(3) Rub-concrete pavement broken rate, the cumulative damage are much lower than normal concrete pavement at the end of service year, and rub-concrete pavement IRI and faulting, are slightly better than normal concrete. Therefore, the rub-concrete pavement has good performance.

\section{Reference}

[1] M.G.Gregory. Analysis And Testing of Waste Tire Fiber Modified Concrete, Louisiana State University, may 2005:3 5.

[2] Han Cun Yu.Economics Comparison of Highway Cement Road Surface and Asphalt Pavement[J].Heilongjiang Transportation Science and Technology.2007,7:6-7.

[3] Li Rui, Wang Ling. The Research Progress of Portland Cement Concrete Containing Crumb Rubber [J].Concrete, 2006, 4:91-95. 
[4] Hou Jie, Gao Pei Wei.Development Prospects of Highway Cement Concrete Pavement [J].Jiang Su Building Materials, 2006, 4:22-24.

[5] Liu Dong Liang,Wang Long, Fan Lu uninfluenced for Rub-concrete Road Performance of Waste Rubber Particles Processing Interface[J].HIGHWAY 2008,10:116-119.

[6] S.Pitil, C.Chalermphol. Concrete Pedestrian Block Containing Crumb Rubber from Recycled Tires.Thammasat Int.J.Sc.Tech., Vol.10, No.2, April-june 2005.

[7] Kang Jing Fu, Ren Hai Bo, hang Pin Zu.Cracing Resistance and Property of Rubberized Concrete [J].Journal of Composite Materials, 2006, 6:158-162.

[8] Sezan Qrak. Investigation of Vibration Damping on Polymer Concrete with Polyester Resin. Cement and concrete research, 2000, 30:171 174.

[9] Bai Wen Feng, Zhang Jian Hua,Wang Xin Li. Study on the Damping Ratio of Glass Fiber Reinforced Polymer Concrete [J]. Design and Research 2007, 10:71-74.

[10] Zhu Han. Adding Crumb Rubber into Exterior Wall Materials [J].Waste Management and Research.2003, 2:20-24.

[11] Ji Tian Jian,Wang Hui,Chen Rong Shen.Fatigue Characteristic of Recycling Cement Concrete[J].Journal of Traffic and Transportation Engineering.2002,2:16-18.

[12] AASHTO Guide for Design of New and Rehabilitated Pavement Structures [R].2002. 